\title{
Key to Translators
}

AG Arie A. Galles

WN Warren Niesłuchowski

xxxvii 


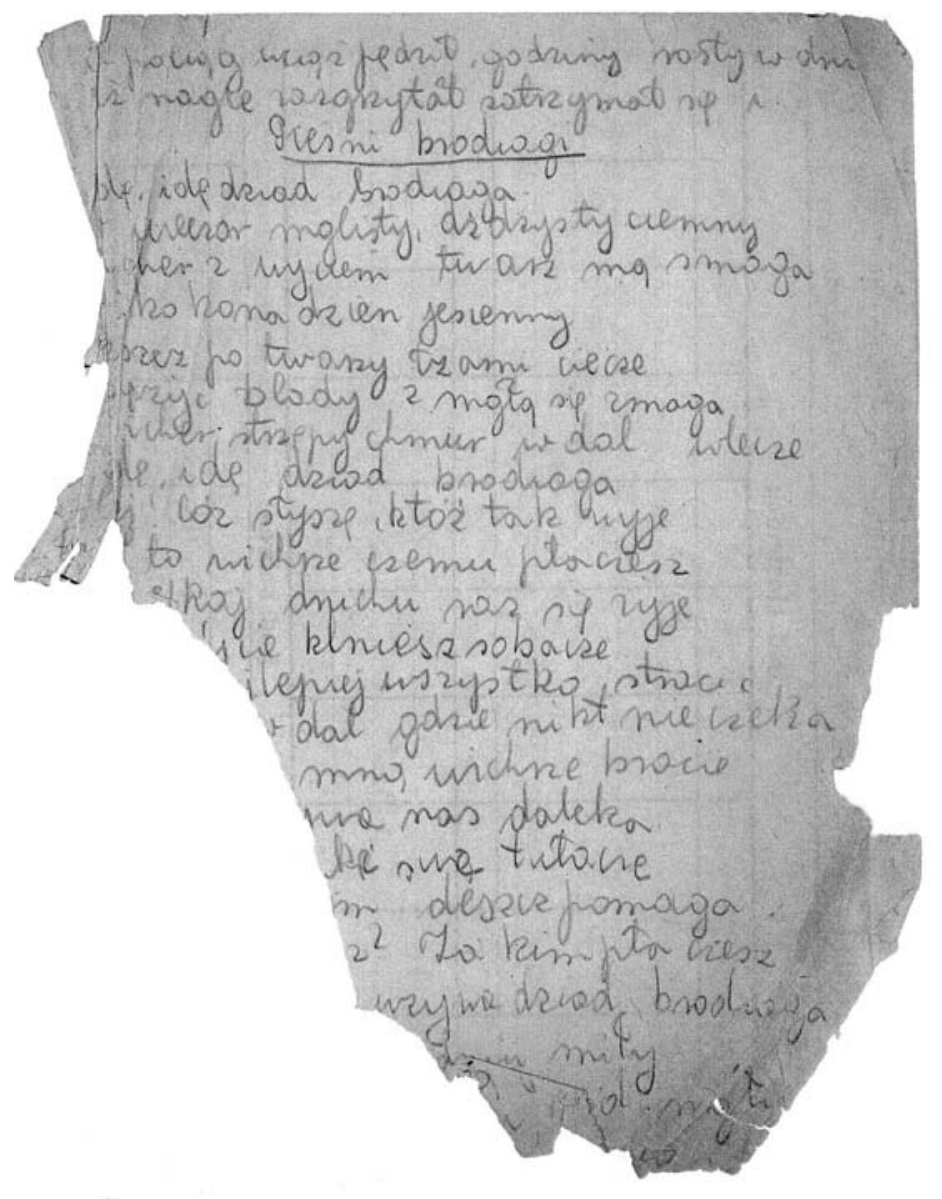

Handwritten manuscript of a poem written by Ilona. 